\title{
Sensitivity Analysis of a 50+ Coal-Fired Power Unit Efficiency
}

\author{
Katarzyna Stępczyńska-Drygas, Sławomir Dykas, Krystian Smołka \\ Institute of Power Engineering and Turbomachinery, Silesian University of Technology, Gliwice, Poland \\ Email: slawomir.dykas@polsl.pl
}

Received 23 November 2015; accepted 21 December 2015; published 24 December 2015

Copyright (C) 2015 by authors and Scientific Research Publishing Inc.

This work is licensed under the Creative Commons Attribution International License (CC BY). http://creativecommons.org/licenses/by/4.0/

c) (i) Open Access

\section{Abstract}

The coal-fired power unit integration with a $\mathrm{CO}_{2}$ capture and compression installation involves a considerable rise in the costs of electricity generation. Therefore, there is a need for a continuous search for methods of improving the electricity generation efficiency in steam power plants. One technology which is especially promising is the advanced ultra-supercritical (A-USC) power unit. Apart from steam parameters upstream the turbine, the overall efficiency also depends on the efficiency values of individual elements of the plant and the size of energy consumption of the process of $\mathrm{CO}_{2}$ sequestration from the boiler flue gases. These problems are considered herein to emphasize that without specifying the efficiency values of the power plant main elements the information concerning its electricity generation efficiency is incomplete. This paper presents the influence of the efficiency of individual elements of the power plant on its electricity generation efficiency. The lack of information of the efficiencies of the power plant individual elements, by presenting its overall efficiency, may lead to the false conclusions.

\section{Keywords}

Sensitivity Analysis, A-USC, Power Unit Efficiency, $\mathrm{CO}_{2}$ Capture

\section{Introduction}

The electricity generation efficiency in coal-fired power plants has an enormous impact on the consumption of fossil fuels and on emissions into the environment. The European reference standard is now set by the conceptual coal-fired Reference Power Plant North Rhine-Westphalia (RPP NRW). Steam parameters upstream the turbine are $28.5 \mathrm{MPa} / 600^{\circ} \mathrm{C} / 620^{\circ} \mathrm{C}$. The power unit gross and net capacity is $600 \mathrm{MW}$ and $556 \mathrm{MW}$, respectively. The plant achieves the net electricity generation efficiency of $45.9 \%$ at the condenser pressure at the level of $4.5 \mathrm{kPa}$ [1]. 
The power industry worldwide has set itself a goal of shifting the net electricity generation efficiency limit for the reference conditions from the current $46 \%$ to $50 \%$ and higher. Reaching this level will require substantial technological changes, especially in the area of the design materials used to make the plant basic elements [2]. Perfecting the power unit steam-water cycle, together with an improvement in the steam turbine internal efficiency and the boiler power efficiency, may contribute essentially to a further rise in overall power efficiency.

The most promising method of improving the efficiency of state-of-the-art coal-fired power units is to raise both live and reheated steam parameters. For every rise in the temperature of live and reheated steam by $20^{\circ} \mathrm{C}$, there is an increase in efficiency by 1 percentage point, and for each increment in the live steam pressure by 1 $\mathrm{MPa}$ - an increase in efficiency by $0.2 \%$ [3]. A rise in the efficiency of the Rankine steam-water cycle can be achieved by: lowering the condenser pressure, raising the final temperature of feed water, increasing the number of stages in the feed water regenerative heaters and using steam superheating and reheating systems correctly. It should also be noted that overall electricity generation efficiency of a steam power unit is affected by internal efficiencies of individual elements of the power engineering machinery and equipment used in the plant. The impact of the internal efficiency of the steam turbine on the overall efficiency of the plant is bigger than that of other elements, and the key factors are as follows: advanced three-dimensional blade design, state-of-the-art manufacture technology and the use of large-size last stage blades to limit stack losses. On the other hand, the boiler power efficiency may be improved by lowering the flue gas temperature, reducing the incomplete and imperfect combustion losses (unburnt carbon loss-UBC), minimizing the pressure and temperature losses and using coal drying. A further rise in the power unit net efficiency can be achieved by a reduction in own-needs electricity consumption (e.g. by using pump and fan drives with rotational speed adjustment). In the case of a coal-fired power unit integrated with an installation of carbon dioxide capture by means of chemical absorption the electricity generation efficiency is hugely affected by the energy consumption of the process of $\mathrm{CO}_{2}$ sequestration from flue gases, which may vary during the power unit service life due to the use of new and better amines [4] [5].

The increment in the electricity generation efficiency from 35\% (for the subcritical power units currently operating in Poland) to $50 \%$ will cause a reduction in unit $\mathrm{CO}_{2}$ emissions from about 984 to 689 kgCO 2 per 1 MWh net generated electricity, i.e. by 30\% (Figure 1). It should be emphasized that the values of emissions and fuel consumption presented in Figure 1 are characteristic of a specific hard coal type (here: hard coal with the calorific value of $23 \mathrm{MJ} / \mathrm{kg}$ and the elemental carbon (C) content of 60\%). For a power unit with the net electric power of 832.5 MW (gross: $900 \mathrm{MW}$ ) this means a reduction in fuel consumption per year (assuming the annual operation time of $7000 \mathrm{~h}$ ) by 782 thousand tons and $\mathrm{CO}_{2}$ emissions smaller by 1720 thousand tons (Figure 2).

Globally, the average efficiency of coal-fired power plants is about 30\%. The average efficiency of power stations in the European Union is close to 38\%. By contrast, the average efficiency of plants in the USA is only 33\% and in China-37\% [6]. However, the issues related to the power plant efficiency have to be considered with care because the actual efficiency of a given unit depends on its location, fuel quality and operating conditions. The basis factor is the cooling conditions and the pressure in the steam turbine condenser resulting from that.
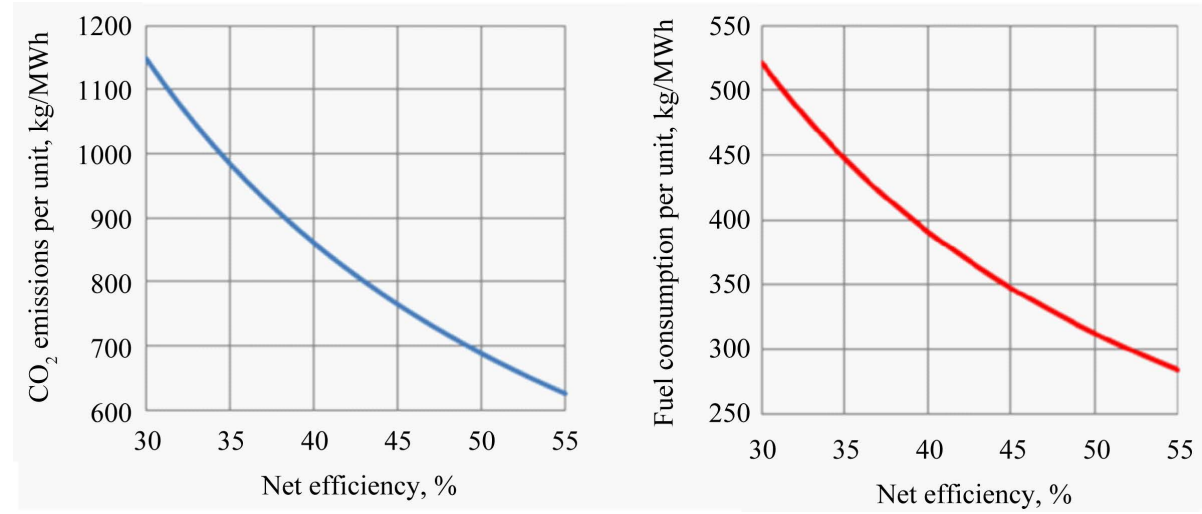

Figure 1. Unit $\mathrm{CO}_{2}$ emissions (left) and unit fuel consumption (right) per unit of net generated electricity depending on net electricity generation efficiency (hard coal with calorific value of $23 \mathrm{MJ} / \mathrm{kg}$ and a $60 \%$ content of $\mathrm{C}$ ). 

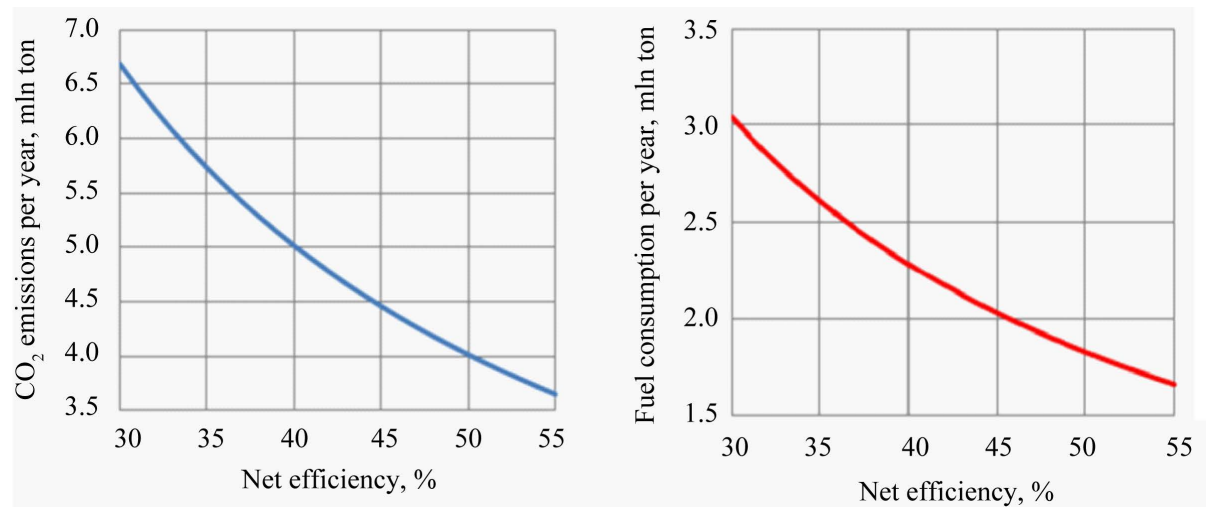

Figure 2. Annual $\mathrm{CO}_{2}$ emissions (left) and annual fuel consumption (right) for a coal-fired power unit with net electric power of $832.5 \mathrm{MW}$ (gross: $900 \mathrm{MW}$ ) assuming the annual operation time of $7000 \mathrm{~h}$ depending on net electricity generation efficiency (hard coal with calorific value of $23 \mathrm{MJ} / \mathrm{kg}$ and a $60 \%$ content of C).

In inland locations in the USA the steam pressure in the condenser is 7 - $9 \mathrm{kPa}$, whereas in European conditions - especially if sea water is used as coolant - the condenser steam pressure may reach the value of up to $3 \mathrm{kPa}$. For this reason, European power stations are characterized by efficiency values by about $2 \%$ higher compared to their American counterparts. The coal quality and the once-through boiler structure, which is common in Europe, may cause a reduction in own-needs energy consumption. Attention should also be paid to the type of the coal calorific value assumed while determining the power unit efficiency-whether it is the lower or higher calorific value (LCV or HCV). The cumulative effect of all these factors, which condition the levels of achieved efficiency, may lead to differences in the obtained values as high as 4 percentage points for seemingly identical plants [7]. Thus a typical subcritical power unit in the USA may be characterized by a $37 \%$ efficiency, whereas a modern supercritical unit may have an efficiency of $42 \%$. For the European conditions, the same values of efficiency may be $41 \%$ and $46 \%$, respectively.

In the case of thermodynamic calculations of cycles of coal-fired power units, the obtained values of the gross and net efficiency of electricity generation depend on assumed values of the input data, i.e. on the boiler power efficiency, the turbine internal efficiency, the condenser pressure, the power unit own-needs index, the pressure loss in the boiler and steam pipelines, the heat loss in regenerative heaters. Therefore, it is essential that all assumptions made for the calculations should be determined precisely.

In order to assess achievable values of the electricity generation gross and net efficiency, a comparison was made of the basic indices of the operation of an ultra-supercritical coal-fired power unit with gross electric power of $900 \mathrm{MW}$ [5] [8] [9]. The impact of the values of efficiency of the power unit individual elements of machinery and equipment and of heat and flow losses in pipelines and heat exchangers on the overall plant electricity generation efficiency was determined. An analysis was also conducted of the sensitivity of the coal-fired power unit efficiency to the energy consumption of the process of $\mathrm{CO}_{2}$ separation from flue gases in the case of a coal-fired power unit integrated with an installation of carbon dioxide capture by means of chemical absorption.

\section{Definitions of Efficiency of Individual Elements of Machinery and Equipment}

The basic parameters and indices of the power unit operation are defined as follows:

- The boiler power efficiency:

$$
\eta_{K}=\frac{\dot{Q}_{u z}}{\dot{P} W_{d}}
$$

where:

$\dot{Q}_{u z}$ : flux of useful heat supplied to the cycle medium in the boiler,

$\dot{P}$ : fuel mass flow,

$W_{d}$ : fuel calorific value in the as-received state. 
- The turbine isentropic efficiency:

$$
\eta_{i T}=\frac{h_{1}-h_{2}}{h_{1}-h_{2 s}}
$$

where:

$h_{1}$ : steam specific enthalpy at the turbine inlet, $h_{2}$ : steam specific enthalpy at the turbine outlet, $h_{2 \mathrm{~s}}$ : steam specific enthalpy at the turbine outlet in the isentropic process.

- The efficiency of regenerative heaters:

$$
\eta_{P R}=\frac{\dot{m}_{1}\left(h_{2}-h_{1}\right)}{\dot{m}_{2}\left(h_{3}-h_{4}\right)}
$$

where:

$\dot{m}_{1}$ : mass flow of heated water,

$h_{1}$ : water specific enthalpy at the heater inlet,

$h_{2}$ : water specific enthalpy at the heater outlet,

$\dot{m}_{2}$ : mass flow of heating steam,

$h_{3}$ : steam specific enthalpy at the heater inlet,

$h_{4}$ : condensate specific enthalpy at the heater outlet.

- The efficiency of pipelines:

$$
\eta_{R}=1-\frac{h_{1}-h_{2}}{h_{1}}
$$

where:

$h_{1}$ : medium specific enthalpy at the pipeline inlet,

$h_{2}$ : medium specific enthalpy at the pipeline outlet.

- Flow losses:

$$
\xi=\frac{p_{1}-p_{2}}{p_{1}}
$$

where:

$p_{1}$ : medium pressure at the pipeline/heat exchanger inlet,

$p_{2}$ : medium pressure at the pipeline/heat exchanger outlet.

- The cycle efficiency:

$$
\eta_{o}=\frac{\dot{Q}_{d}-\dot{Q}_{w}}{\dot{Q}_{d}}
$$

where:

$\dot{Q}_{d}$ : heat flux supplied to the cycle,

$\dot{Q}_{w}$ : heat flux extracted from the cycle.

- Gross electricity generation efficiency:

$$
\eta_{e l B}=\frac{N_{e l B}}{\dot{P} W_{d}}
$$

where:

$N_{e l B}$ : gross electric power of the power unit.

- Net electric power:

$$
N_{e l N}=N_{e l B}-N_{P W}=N_{e l B}(1-\varepsilon)
$$

where:

$N_{P W}$ : power unit own-needs electric power, $\varepsilon$ : power unit own-needs index. 
- Net electricity generation efficiency:

$$
\eta_{e l N}=\frac{N_{e l N}}{\dot{P} W_{d}}
$$

\section{The Reference 900 MW Power Unit for Advanced Ultra-Supercritical Steam Parameters}

\subsection{Basic Parameters of the Conceptual 900 MW Power Unit}

The flowchart of the conceptual reference advanced ultra-supercritical power unit is presented in Figure 3 . The conceptual power unit with gross electric power of $900 \mathrm{MW}$ is fired with hard coal with a calorific value of 23 $\mathrm{MJ} / \mathrm{kg}$. The composition of coal in the as-received state is presented in Table 1. Complete and perfect combustion is assumed. It is further assumed that the excess air factor in the boiler is $\lambda=1.2$. The composition of wet flue gases is presented in Table 2. The live and reheated steam parameters before the turbine are $35 \mathrm{MPa} / 700^{\circ} \mathrm{C}$ and $7.43 \mathrm{MPa}(\mathrm{a}) / 720^{\circ} \mathrm{C}$, respectively. The power unit basic parameters are listed in Table 3 . Table 4 presents parameters of the feed water regenerative heaters. The basic indices of the power unit operation are listed in Table 5. For the presented system with the gross electric power of $900 \mathrm{MW}$, the values of the achieved gross and net electricity generation efficiency are $52.61 \%$ and $49.04 \%$, respectively.

\subsection{Reference Structure of a Power Unit Integrated with a $\mathrm{CO}_{2}$ Capture Installation}

The basic diagram of a cycle integrated with a $\mathrm{CO}_{2}$ capture and compression installation is presented in Figure 4. The steam needed for the sorbent regeneration is extracted from the main turbine IP/LP crossover pipe. Due to the fact that more than half of the mass flow from the IP/LP crossover pipe is directed to the $\mathrm{CO}_{2}$ capture installation, the low-pressure turbine is reduced from two to one double-flow part. The reboiler feed steam condensate is returned and introduced into the cycle in the low-pressure regeneration region. Taking account of the limitations concerning the maximum size of the absorption columns, the capture installation is composed of four parallel absorber-desorber-compressor lines. The steam needed for the sorbent regeneration is extracted from the

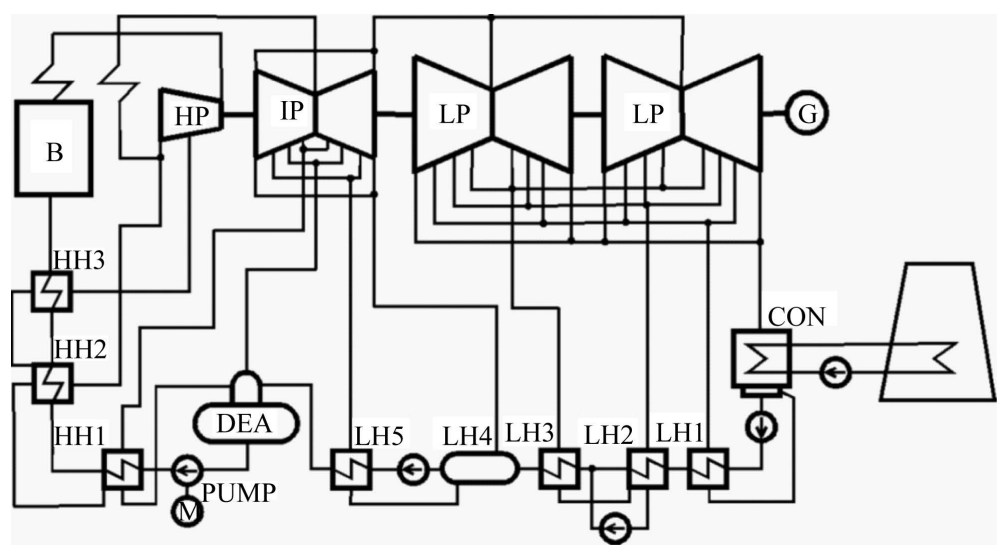

Figure 3. Flowchart of the reference advanced ultra-supercritical power unit.

Table 1. Fuel composition-coal 23.

\begin{tabular}{cccccccc}
\hline $\mathrm{w}$ & $\mathrm{p}$ & $\mathrm{c}$ & $\mathrm{h}$ & $\mathrm{o}$ & $\mathrm{n}$ & & \\
\hline 0.09 & 0.2 & 0.6 & 0.038 & 0.054 & 0.013 \\
\hline
\end{tabular}

Table 2.Wet flue gas composition.

\begin{tabular}{cccccrr}
\hline $\mathrm{CO}_{2}$ & $\mathrm{SO}_{2}$ & $\mathrm{O}_{2}$ & $\mathrm{~N}_{2}$ & $\mathrm{H}$ & $\mathrm{H}$ & \\
\hline 0.1416 & 0.0009 & 0.0329 & 0.7378 & 0.078 & 0.0088 \\
\hline
\end{tabular}


Table 3. Basic figures for the reference 900 MW advanced ultra-supercritical power unit developed within the project.

\begin{tabular}{|c|c|c|}
\hline Parameter & & Unit \\
\hline Live steam temperature at the boiler outlet & 702 & ${ }^{\circ} \mathrm{C}$ \\
\hline Live steam temperature at the turbine inlet & 700 & ${ }^{\circ} \mathrm{C}$ \\
\hline Live steam pressure at the boiler outlet & 35.8 & MPa \\
\hline Live steam pressure at the turbine inlet & 35 & MPa \\
\hline Reheated steam temperature at the boiler outlet & 721 & ${ }^{\circ} \mathrm{C}$ \\
\hline Reheated steam temperature at the turbine inlet & 720 & ${ }^{\circ} \mathrm{C}$ \\
\hline Reheated steam pressure at the boiler outlet & 7.5 & MPa \\
\hline Steam pressure in the IP/LP crossover pipe & 0.5 & MPa \\
\hline Feed water temperature & 330 & ${ }^{\circ} \mathrm{C}$ \\
\hline Internal efficiency of the turbine HP part stage groups & 90 & $\%$ \\
\hline Internal efficiency of the turbine IP part stage groups & 92 & $\%$ \\
\hline Internal efficiency of the turbine LP part stage groups (the efficiency value is corrected due to the stack loss) & 92 & $\%$ \\
\hline Stack loss & 20 & $\mathrm{~kJ} / \mathrm{kg}$ \\
\hline Flue gas temperature at the boiler outlet & 110 & ${ }^{\circ} \mathrm{C}$ \\
\hline The boiler power efficiency & 95 & $\%$ \\
\hline Excess air factor & 1.2 & - \\
\hline Hard coal calorific value & 23 & $\mathrm{MJ} / \mathrm{kg}$ \\
\hline Generator efficiency & 98.8 & $\%$ \\
\hline The turbine mechanical losses & 0.9 & MW \\
\hline Efficiency of feed water pumps & 85 & $\%$ \\
\hline Efficiency of regenerative exchangers & 99.5 & $\%$ \\
\hline Flow losses in steam pipelines to regenerative exchangers & 2 & $\%$ \\
\hline Losses of the feed water flow through regenerative exchangers & 1 & $\%$ \\
\hline The cycle medium pressure drop in the boiler & 4.3 & MPa \\
\hline Pressure drop of interstage steam in the boiler reheater & 0.2 & MPa \\
\hline Flow losses in reheated steam pipelines & 1 & $\%$ \\
\hline Flow losses between the turbine IP and LP part & 1 & $\%$ \\
\hline The power unit gross electric power (at the generator terminals) & 900 & MW \\
\hline Internal efficiency of the feed water and condensate pumps & 85 & $\%$ \\
\hline Internal efficiency of the cooling water pumps & 82 & $\%$ \\
\hline Efficiency of air and flue gas fans & 85 & $\%$ \\
\hline Energy consumed by coal mills per kg of coal & 90 & $\mathrm{~kJ} / \mathrm{kg}$ \\
\hline Efficiency of electric motors driving auxiliary equipment & 97 & $\%$ \\
\hline Efficiency of the rotational speed adjustment & 96 & $\%$ \\
\hline Efficiency of the unit transformer & 99.5 & $\%$ \\
\hline Ambient temperature & 14 & ${ }^{\circ} \mathrm{C}$ \\
\hline Ambient pressure & 98 & hPa \\
\hline The condenser cooling water temperature & 19.1 & ${ }^{\circ} \mathrm{C}$ \\
\hline Increment in the cooling water temperature & 9 & $\mathrm{~K}$ \\
\hline Temperature difference in the condenser & 2.8 & K \\
\hline Pressure in the condenser & 4.5 & $\mathrm{kPa}$ \\
\hline Heat from the machinery and equipment cooling as a percentage of heat extracted in the condenser & 4 & $\%$ \\
\hline
\end{tabular}


Table 4. Parameters of the regenerative water heaters.

\begin{tabular}{|c|c|c|c|c|c|c|c|c|c|}
\hline Heater & PN1 & PN2 & PN3 & PN4 & PN5 & ODG & PW1 & PW2 & PW3 \\
\hline Bleed steam pressure, $\mathrm{kPa}$ & 22.2 & 78.5 & 212 & 490 & 1228 & 2364 & 4542 & 7622 & 13,192 \\
\hline Temperature difference, $\mathrm{K}$ & 3 & 3 & 3 & - & 3 & - & 2 & 2 & 2 \\
\hline Condensate supercooling, K & - & - & 10 & - & 10 & - & 10 & 10 & 10 \\
\hline
\end{tabular}

Table 5. Basic indices of the 900 MW power unit operation.

Live steam mass flow

Heat flux given up in the condenser

Auxiliary equipment cooling heat (4\% of heat in the condenser)

Cooling water mass flow

Fuel mass flow

Flue gas mass flow at the boiler outlet

$\mathrm{CO}_{2}$ mass flow at the boiler outlet

$\mathrm{CO}_{2}$ emissions per unit of net generated electricity

Gross electric power

Gross electricity generation efficiency

Net electric power

Net electricity generation efficiency

Own-needs index
$578.42 \mathrm{~kg} / \mathrm{s}$

743.1 MW

$29.5 \mathrm{MW}$

$20,532 \mathrm{~kg} / \mathrm{s}$

$74.4 \mathrm{~kg} / \mathrm{s}$

$776.4 \mathrm{~kg} / \mathrm{s}$

$163.3 \mathrm{~kg} / \mathrm{s}$

$701 \mathrm{gCO}_{2} / \mathrm{kWh}$

$900 \mathrm{MW}$

$52.61 \%$

838.8 MW

$49.04 \%$

$6.79 \%$

turbine IP/PL crossover pipe. The temperature difference in the evaporator (REB) between condensing steam and the sorbent regeneration temperature $\left(124^{\circ} \mathrm{C}\right)$ is $10 \mathrm{~K}$. Therefore, the required parameters of the heating steam are $134^{\circ} \mathrm{C}$ and $0.33 \mathrm{MPa}$ (considering flow losses at the level of $8 \%$ ). Such parameters have to be kept constant in the entire range of the power unit load. It is assumed in the basic calculations that the pressure in the IP/LP crossover pipe of the integrated and the reference power units is identical and totals $0.5 \mathrm{MPa}$.

Table 6 presents the basic operating indices of the reference power unit (with no $\mathrm{CO}_{2}$ capture installation) and of the integrated one. Assuming an identical mass flow of live steam as in the reference power unit (578.42 kg/s) and an identical pressure in the turbine IP/LP crossover pipe, the integrated power unit achieves the net electric power of $636.9 \mathrm{MW}$ and the net efficiency of $37.23 \%$. The drop in the net efficiency totals $11.82 \%$ and in the net electric power-202 MW, $57 \mathrm{MW}$ of which is the power needed to drive $\mathrm{CO}_{2}$ compressors and $6 \mathrm{MW}$ - the driving power of the capture installation auxiliary equipment (fans, pumps). The other $139 \mathrm{MW}$ is the effect of the reduction in the steam turbine power due to the considerable mass flow of steam extracted from the IP/LP crossover pipe for the sorbent regeneration and of the rise in power needed to drive the cooling water pumps.

\subsection{Assessment of the Power Unit Efficiency for Different Assumptions}

In order to present changes in the steam power unit efficiency resulting from changes in the efficiency of its individual elements, the typical range of changes in efficiency of the basic components of the steam turbine installation was applied. The minimum and maximum efficiency values of the power unit elements are listed in Table 7 and Table 8. The calculations were performed for the analyzed structure of the 50+ power unit using the following variants:

1) The efficiencies of all machinery and equipment elements total $100 \%$ and the heat and flow losses in pipelines and exchangers are 0.

2) The efficiencies of all machinery and equipment elements are assumed at the maximum currently achievable level (Table 7) and the heat and flow losses in bleed steam pipelines and in exchangers are assumed 


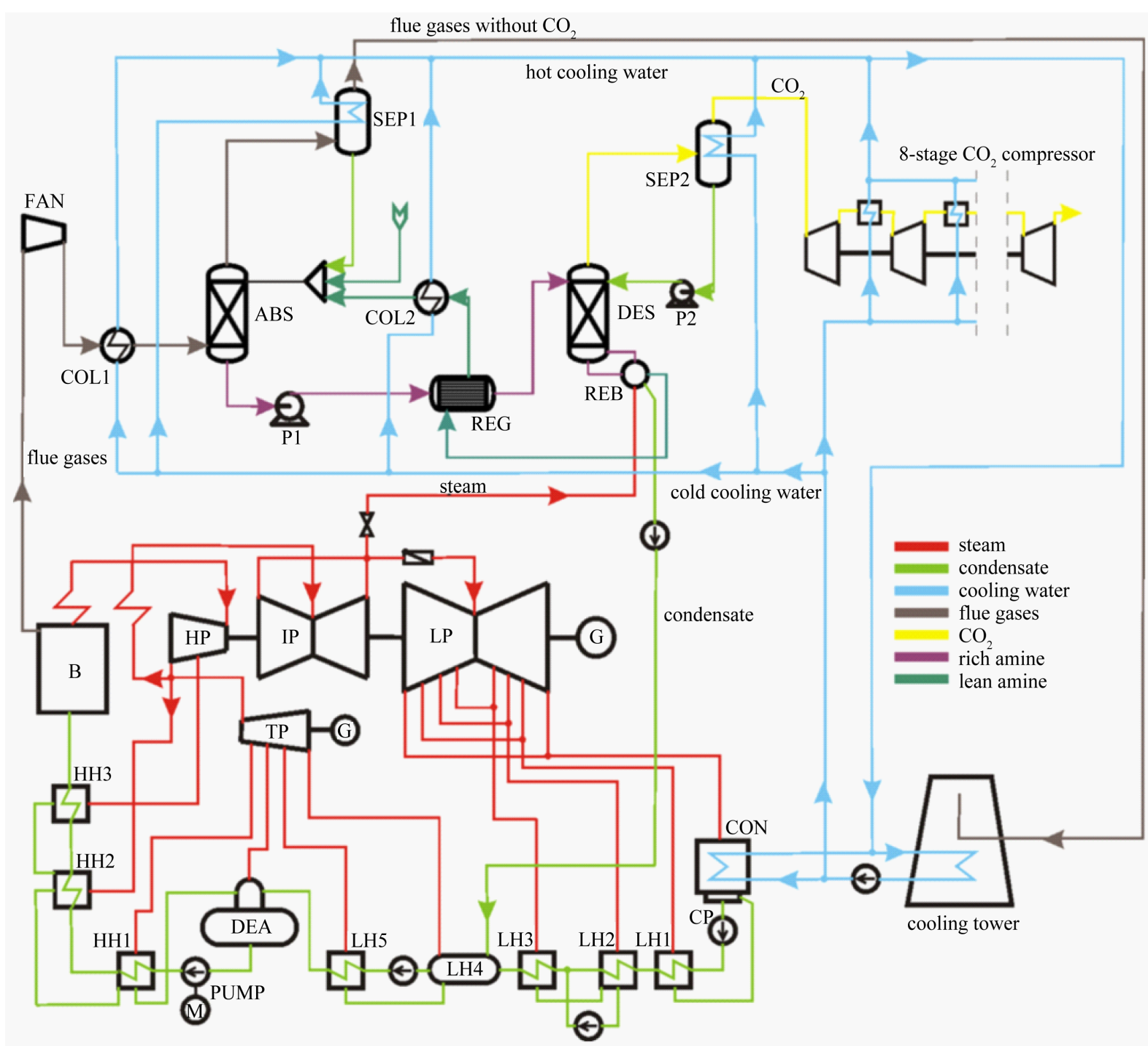

B - steam boiler; HP, IP, LP - the turbine HP, IP and LP part, CON - condenser; HH - high-pressure regeneration heater;

LH - low-pressure regeneration heater; PUMP - feed pump; CP - condensate pump; G - generator;

ABS - absorber; DES - desorber; REB - reboiler; REG - cross-flow heat exchanger; FAN - flue gas fan;

COL1 - flue gas precooler; COL2 - lean amine cooler; SEP1 - flue gas moisture separator, flue gas cooler;

$\mathrm{SEP} 2-\mathrm{CO}_{2}$ moisture separator and $\mathrm{CO}_{2}$ cooler; $\mathrm{P} 1$ - rich amine pump; P2 - lean amine pump

Figure 4. Diagram of the $900 \mathrm{MW}$ power unit with the $\mathrm{CO}_{2}$ capture and compression installation.

according to Table 3.

3) The efficiencies of all machinery and equipment elements and the heat and flow losses in bleed steam pipelines and in exchangers are assumed according to Table 3.

4) The efficiencies of all machinery and equipment elements are assumed at the minimum level (Table 8) and the heat and flow losses in bleed steam pipelines and in exchangers are assumed according to Table 3.

The calculation results are listed in a table. Figure 5 presents the gross and net electricity generation efficiency for three calculation variants: MAX (maximum), REF (reference) and MIN (minimum). Figure 6 presents the share of the power unit individual elements in the difference between the cycle efficiency determined assuming $100 \%$ efficiency of all the machinery and equipment and zero heat and pressure losses (calculation variant 1, Table 9) and the gross and net electricity generation efficiency for the REF variant. Figure 7 presents the share of the power unit individual elements in the increase in the net electricity generation efficiency from the calculation variant MIN to variant MAX. 
Table 6. Basic operating indices of the reference power unit (with no $\mathrm{CO}_{2}$ capture installation) and of the integrated one (hard coal 23).

\begin{tabular}{|c|c|c|c|}
\hline Parameter & Unit & Reference power unit & Integrated power unit \\
\hline Nominal pressure in the IP/LP crossover pipe & $\mathrm{MPa}$ & 0.5 & 0.5 \\
\hline Live steam mass flow & $\mathrm{kg} / \mathrm{s}$ & 578.42 & 578.42 \\
\hline Steam mass flow directed to the $\mathrm{CO}_{2}$ capture installation & $\mathrm{kg} / \mathrm{s}$ & 0 & 205.5 \\
\hline Heat flux given up in the turbine condenser & MW & 741.9 & 363.2 \\
\hline Waste heat flux from the $\mathrm{CO}_{2}$ capture and compression installation & MW & 0 & 552 \\
\hline Heat flux given up in the cooling tower & MW & 771.4 & 944.7 \\
\hline Gross electric power & MW & 900 & 765.6 \\
\hline Gross electricity generation efficiency & $\%$ & 52.58 & 44.66 \\
\hline Net electric power & MW & 838.8 & 636.9 \\
\hline Net electricity generation efficiency & $\%$ & 49.04 & 37.23 \\
\hline
\end{tabular}

Table 7. Maximum achievable efficiencies of individual elements of machinery and equipment.

$\begin{array}{ll}\text { Steam boiler } & 95 \% \\ \text { HP turbine } & 94 \% \\ \text { IP turbine } & 97 \% \\ \text { LP turbine } & 95 \% \\ \text { Generator } & 99 \%\end{array}$

Live and reheated steam pipelines

$99.9 \%$

Table 8. Minimum assumed efficiencies.

$\begin{array}{lc}\text { Steam boiler } & 92 \% \\ \text { HP turbine } & 88 \% \\ \text { IP turbine } & 90 \% \\ \text { LP turbine } & 88 \% \\ \text { Generator } & 98.5 \% \\ \text { reheated steam pipelines } & 99.5 \%\end{array}$

Table 9. Gross electricity generation efficiency $\left(\eta_{\mathrm{elB}}\right)$ and drop in gross efficiency $\left(\Delta \eta_{\mathrm{elB}}\right)$ compared to variant 1.

\begin{tabular}{ccc}
\hline Calculation variant & Gross electricity generation efficiency, [\%] & $\begin{array}{c}\text { Drop in efficiency compared to variant } 1, \\
\text { percentage points }\end{array}$ \\
\hline 1 & 59.54 & - \\
(MAX) 2 & 53.84 & 5.7 \\
(REF) 3 & 52.61 & 6.93 \\
(MIN) 4 & 49.18 & 10.36 \\
\hline
\end{tabular}

\subsection{The Impact of Energy Consumption of the $\mathrm{CO}_{2}$ Capture Process on the Power Unit Operating Parameters}

The energy consumption of the $\mathrm{CO}_{2}$ capture process (or of the sorbent regeneration process to be exact) is a very 


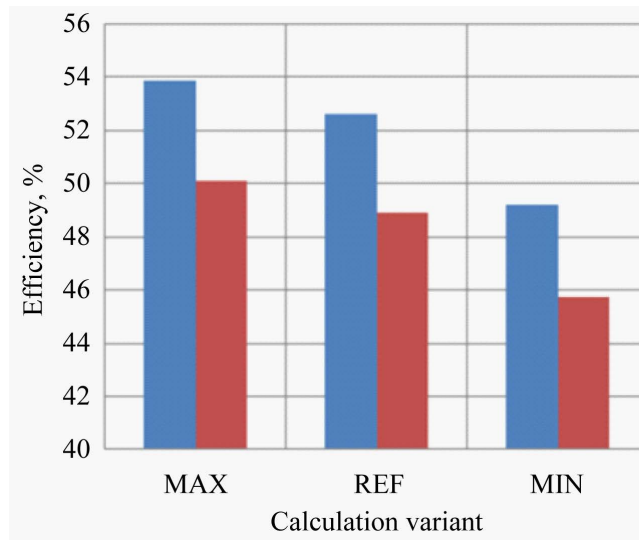

- Gross efficiency

- Net efficiency

Figure 5. Gross and net electricity generation efficiency (own-needs index: 7\%) for three calculation variants: MAX, REF and MIN.

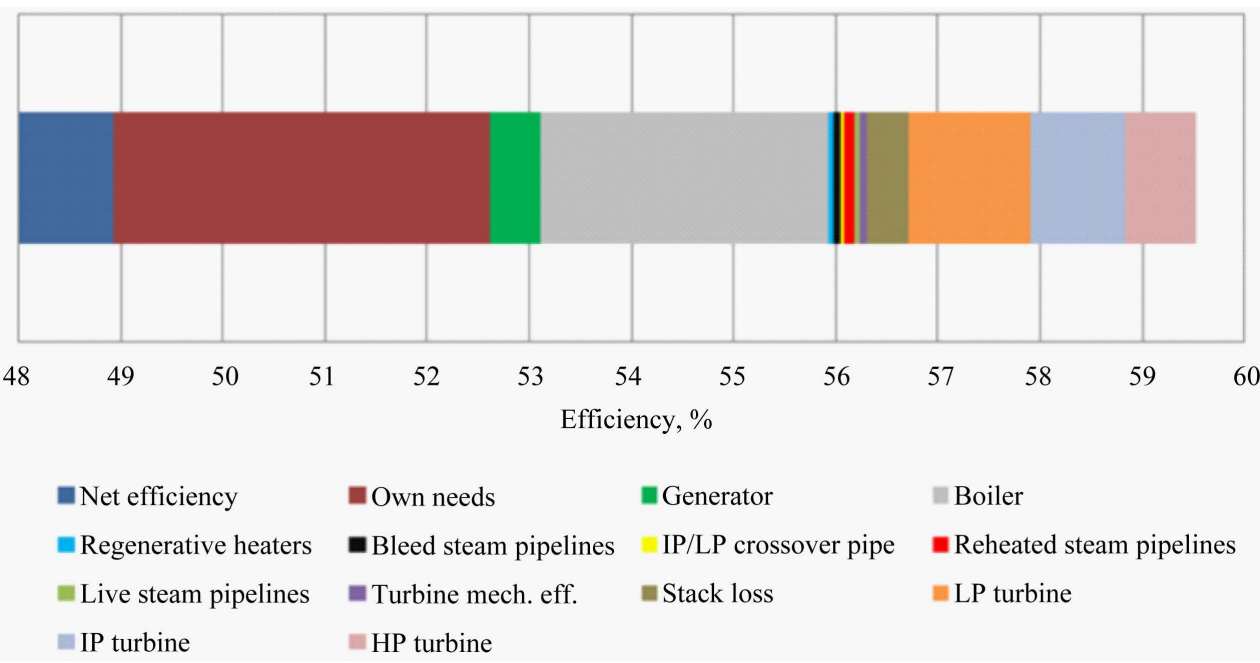

Figure 6. Share of individual elements in the difference between the reference Clausius-Rankine cycle efficiency (calculation variant 1 from Table 9) and net electricity generation efficiency for the REF calculation variant.

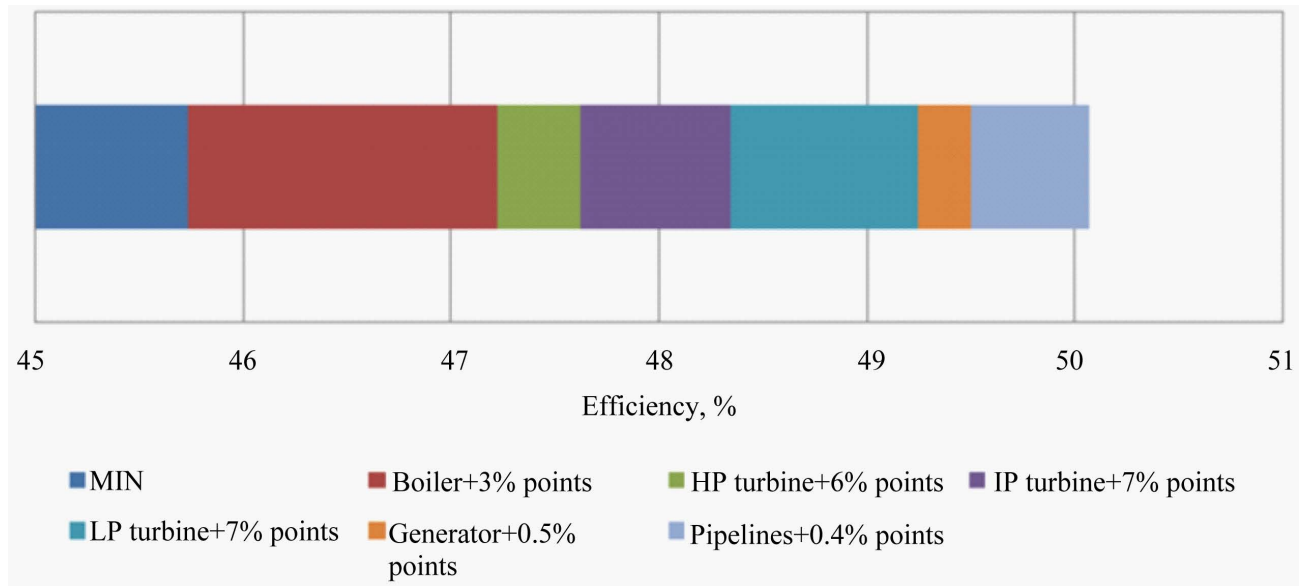

Figure 7. Share of individual elements in the increase in net electricity generation efficiency from the MIN calculation variant to variant MAX (in the legend the rise in efficiencies of the power unit individual elements is marked in respect of variant MIN). 
important factor that affects both the integrated power unit electricity generation efficiency and the economic indices. Figure 8 presents the impact of the capture process energy consumption on the decrease in the net electric power and on the drop in the net electricity generation efficiency after the power unit integration with the $\mathrm{CO}_{2}$ capture installation. Figure 9 shows costs of electricity generation in a power unit integrated with a $\mathrm{CO}_{2}$ capture installation for four values of the capture process energy consumption assuming that the price of $\mathrm{CO}_{2}$ emissions allowances is at the level of $40 €$. For energy consumption of $3.5 \mathrm{MJ} / \mathrm{kgCO}_{2}$ the costs are 90.10 $€ / \mathrm{MWh}$, and for the consumption of $2 \mathrm{MJ} / \mathrm{kgCO}_{2}$ - they drop to $82.99 € / \mathrm{MWh}$. The chart in Figure 10 illustrates changes in marginal costs of electricity generation depending on the price of $\mathrm{CO}_{2}$ emissions allowances for a power unit with no capture installation and for a power unit integrated with such an installation with different values of the process energy consumption. For the energy consumption index of $3.5 \mathrm{MJ} / \mathrm{kg}$, the limit price of the allowances is $60 € / \mathrm{t}$, and for the index of $2 \mathrm{MJ} / \mathrm{kg}$ it is lower and totals $48 € / \mathrm{t}$.

The charts presented above indicate clearly that the $\mathrm{CO}_{2}$ capture process energy consumption has a huge impact on the economic aspect of operating a coal-fired power unit integrated with a CCS system. In view of the

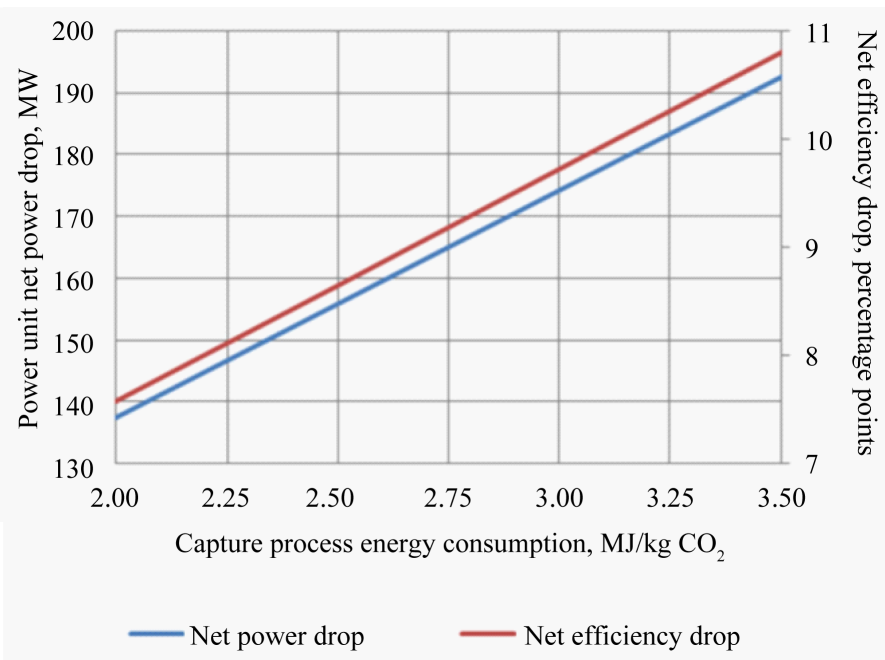

Figure 8. Drop in net electric power and in net electricity generation efficiency after the power unit integration with a $\mathrm{CO}_{2}$ capture installation depending on the capture process energy consumption.

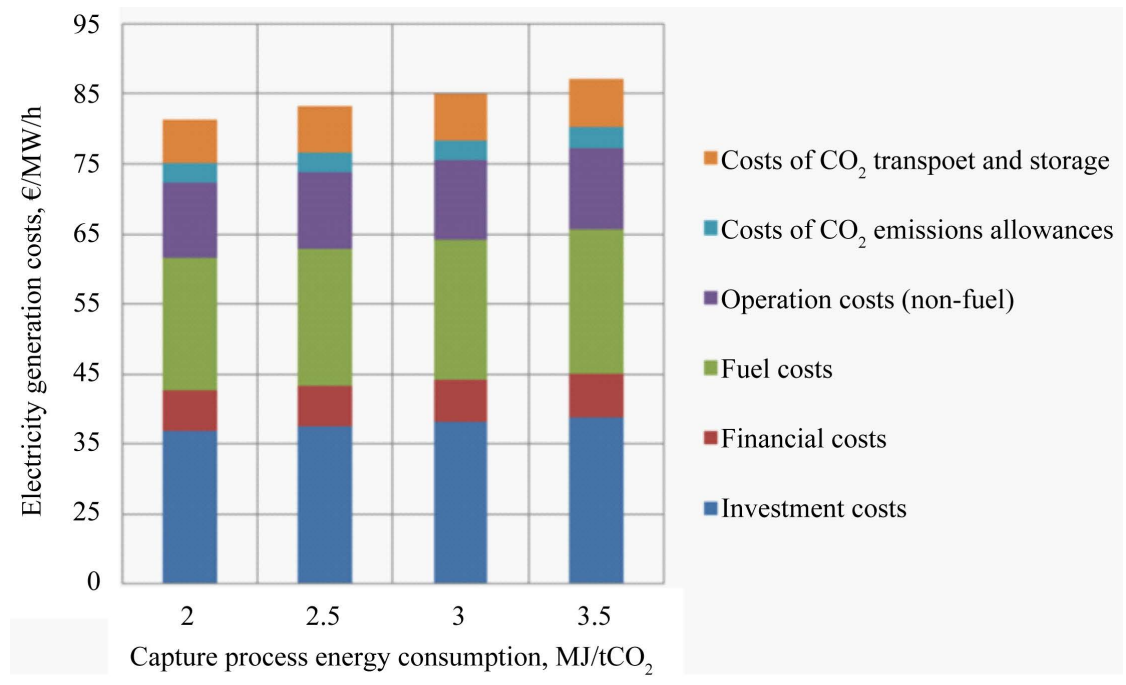

Figure 9. Costs of electricity generation-power unit with a $\mathrm{CO}_{2}$ capture installation (price of $\mathrm{CO}_{2}$ emissions allowances: $40 €$ )-for different values of the $\mathrm{CO}_{2}$ capture process energy consumption. 


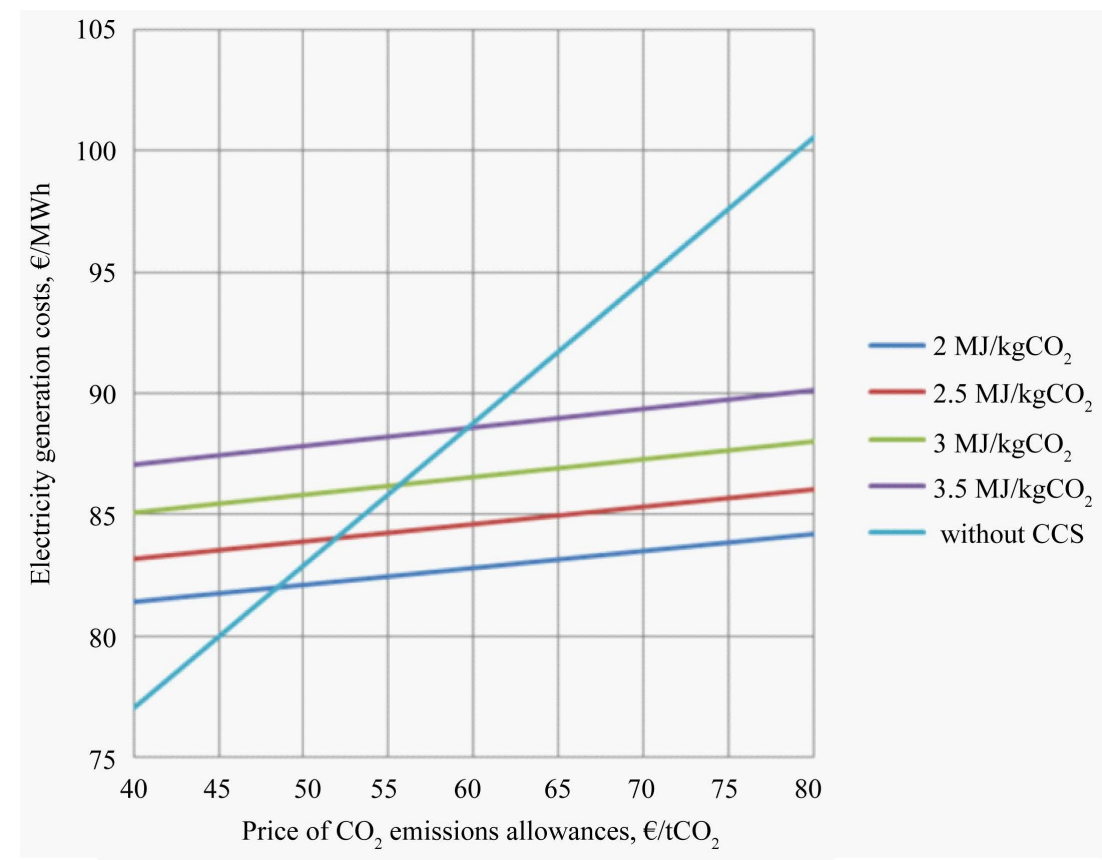

Figure 10. Marginal costs of electricity generation for a power unit with and without a $\mathrm{CO}_{2}$ capture installation for different values of the $\mathrm{CO}_{2}$ capture process energy consumption depending on the price of $\mathrm{CO}_{2}$ emissions allowances.

continuous development and improvement in the technologies of carbon dioxide capture from flue gases by means of chemical absorption, e.g. by using better sorbents, it is very unlikely that the $\mathrm{CO}_{2}$ capture process energy consumption will remain constant during the power plant entire service life. On the contrary, it is rather bound to decrease.

\section{Conclusions}

In this paper it shows an influence of efficiency of turbine, boiler and other elements of power cycle on its overall efficiency. Presenting the electricity generation efficiency without any information about the efficiency of the individual elements, main elements like turbine or boiler of the power plant are unfounded and may give wrong information about the effectiveness of considered technology of electricity generation.

The need to reduce emissions of greenhouse gases and improve the economy of electricity generation resulted in substantial and on-going progress in the field of condensing coal-fired power units. The development of coalbased technologies is now oriented towards achieving higher and higher powers and electricity generation efficiencies. The great step forward in materials engineering has made implementation of the advanced ultra-supercritical (A-USC) power unit technology more and more common. Due to the current state of knowledge concerning the turbine design and the strength properties of available operating materials, the maximum achievable steam parameters in steam power units are $30 \mathrm{MPa}$ and $600^{\circ} \mathrm{C}$ for live steam and $620^{\circ} \mathrm{C}$ for reheated steam. It is estimated that using such steam parameters, the net electricity generation efficiency may reach $48 \%$, depending on the power plant location (cooling conditions) and on the solutions applied to bring about a further improvement in efficiency.

A significant increase in the live and reheated steam parameters (from current $30 \mathrm{MPa} / 600^{\circ} \mathrm{C} / 620^{\circ} \mathrm{C}$ to e.g. 35 $\mathrm{MPa} / 700^{\circ} \mathrm{C} / 720^{\circ} \mathrm{C}$ ) will result in a rise in the net electricity generation efficiency by $2.5 \sim 3$ percentage points, which is essential in terms of the reduction in the fossil fuel consumption, emissions of greenhouse gases and profitability of investments related the power unit integrated with a $\mathrm{CO}_{2}$ capture installation. A further rise in efficiency will be impossible without optimization of the steam cycle structure, improvement in the design of turbines, boilers and regeneration systems, optimization of the cold end, minimization of the consumption of energy needed to satisfy the power unit own needs and the use of low-temperature waste heat.

Ecologically, respecting the limits of discharge and emission of pollutants from power engineering installa- 
tions and—economically—satisfying the requirements related to the investment profitability should make it possible for the net electricity generation efficiency of coal-fired "capture ready" plants with a power capacity higher than $300 \mathrm{MW}_{\mathrm{el}}$ to exceed 48 percentage points before the plant is actually integrated with the $\mathrm{CO}_{2}$ capture and compression installation so that the integration carried out later should bring economic profits. Such efficiency values can only be achieved by optimum technological structures if the best available technologies (BATs) are applied in the field of power engineering machinery and equipment. The paper presents the impact of the efficiency of individual elements of the power unit machinery and equipment on the plant overall efficiency. It can be seen that giving values of the power unit electricity generation efficiency without specifying the efficiencies of the unit main components is burdened with a considerable margin of uncertainty which may even be as high as several percentage points.

\section{Acknowledgements}

The results presented in this paper were obtained from research work co-financed by the Polish National Centre of Research and Development in the framework of Contract SP/E/1/67484/10-Strategic Research Programme -Advanced technologies for energy generation: Development of a technology for highly efficient zero-emission coal-fired power units integrated with $\mathrm{CO}_{2}$ capture.

\section{References}

[1] Rosenkranz, J. and Wichtmann, A. (2005) Balancing Economics and Environmental Friendliness-The Challenge for Supercritical Coal-Fired Power Plants with Highest Steam Parameters in the Future.

http://www.energy.siemens.com/mx/pool/hq/energy-topics/pdfs/en/steam-turbines-power-plants/2 Balancing economi cs.pdf

[2] Smołka, K., Stępczyńska-Drygas, K., Dykas, S. and Wróblewski W. (2014) Machinery and Equipment for an Advanced Ultra-Supercritical Coal-Fired Power Unit. Proceedings of the 8th International Science and Technology Conference “Energetyka 2014”, Wrocław, 5-7 November 2014, 107-117 (in Polish).

[3] Breeze, P. (2012) Raising Steam Plant Efficiency_Pushing the Steam Cycle Boundaries. PEI Magazine, 20, 16-20.

[4] Pfaff, I., Oexmann, J. and Kather, A. (2010) Optimised Integration of Post-Combustion $\mathrm{CO}_{2}$ Capture Process in Greenfield Power Plants. Energy, 35, 4030-4041. http://dx.doi.org/10.1016/j.energy.2010.06.004

[5] Stępczyńska-Drygas, K., Dykas, S., Łukowicz, H. and Czaja, D. (2014) Assessment of the Impact of a Coal-Fired Power Unit Integration with a $\mathrm{CO}_{2}$ Capture Installation on Operation under Varied Load Conditions. Proceedings of the International Science and Technology Conference GRE 2014, Szczyrk, 16-18 June 2014, 98 (in Polish).

[6] Electric Power Research Institute (2012) Outlook 2011. Electric Power Research Institute, Palo Alto.

[7] Leyzerovich, A. (2005) Steam Turbines for Modern Fossil-Fuel Power Plants. The Fairmont Press Inc., Liburn.

[8] Stępczyńska-Drygas, K., Lukowicz, H. and Dykas, S. (2013) Calculation of an Advanced Ultra-Supercritical Power Unit with a $\mathrm{CO}_{2}$ Capture Installation. Energy Conversion and Management, 74, 201-208. http://dx.doi.org/10.1016/j.enconman.2013.04.045

[9] Stępczyńska-Drygas, K., Bochon, K., Dykas, S., Łukowicz, H. and Wróblewski, W. (2013) Operation of a Conceptual A-USC Power Unit Integrated with a $\mathrm{CO}_{2}$ Capture Installation at Part Load. Journal of Power Technologies, 93, 383394. 